Research Article

\title{
Parametric Study of Fuel Distribution Effects on a Kerosene-Based Scramjet Combustor
}

\author{
Jun Yang, Xian-yu Wu, and Zhen-guo Wang \\ Science and Technology on Scramjet Laboratory, National University of Defense Technology, Changsha, Hunan 410073, China \\ Correspondence should be addressed to Jun Yang; yj_npu@163.com
}

Received 11 January 2016; Revised 30 May 2016; Accepted 2 June 2016

Academic Editor: James J. McGuirk

Copyright ( 2016 Jun Yang et al. This is an open access article distributed under the Creative Commons Attribution License, which permits unrestricted use, distribution, and reproduction in any medium, provided the original work is properly cited.

\begin{abstract}
Generally, the overall performance of scramjet combustor is greatly impacted by the fuel distribution scheme. The current paper mainly conducted a comprehensive parametric study of the impact of fuel distribution on the overall performance of a kerosenebased scramjet combustor. Herein, a 3D supersonic combustor with a recessed cavity and four injection orifices was taken into consideration. The combustor's performance was analyzed by 3D RANS model. The fuel equivalence ratio for each injection port was taken as the design variables. And the combustion efficiency, the total pressure recovery coefficient, and the drag coefficient were chosen as the objective functions. Some novel data mining methods including DOE technique, Kriging approximation model, interaction analysis, and main effects analysis methods were employed to conduct the parametric study. The distributed fuel injection scheme was optimized by nondominated sorting genetic algorithm. The results show that three objective functions were remarkably affected by both of the total fuel equivalence ratio and the fuel distribution scheme. The objective functions cannot reach the optimal solution at the same time, and there must be a tradeoff among the objective functions.
\end{abstract}

\section{Introduction}

Owing to higher combustion efficiency and specific impulse compared to other propulsion systems such as the rocket engine and the turbine engine under hypersonic conditions, the scramjet engine is expected to be a main engine for the future hypersonic vehicle [1]. Because of its high volumetric energy density, liquid fuel (such as kerosene) has great potential advantage over gas fuel (such as hydrogen). Thus, the liquid-fuel-based, especially the kerosene-based, scramjet engine has got more and more attractions [2]. As a critical component of scramjet, the combustor has a very important influence on scramjet and entire hypersonic vehicle. Supersonic combustion technology is a key enabling technology for sustained hypersonic flights [3]. In this paper, parametric study of a kerosene-based scramjet combustor was taken into consideration carefully to explore the combustor's overall performance.

The length of supersonic combustor should be limited to be less than one meter to increase thrust-weight ratio. And, then, the residence time of air within the scramjet combustor is typically on the order of one millisecond when $6<\mathrm{Ma}$
$<8$ [3]. Thus, the liquid fuel should go through the process of injection, evaporation, mixing with air, and combustion within such short residence time. So far, there are still lots of difficulties to be resolved to enhance supersonic combustor performance due to the lack of theoretic knowledge and experimental approaches [4].

Many efforts, both experimentally [4-8] and numerically [9-16], have been directed to scramjet combustor study since 1960s to explore the performance of supersonic combustor. With the huge advancement of CFD technique, the numerical simulation method has become a very important tool for the research on scramjet combustor [13, 15]. Ebrahimi et al. [12] had conducted comprehensive numerical study on scramjet combustor based on gaseous ethylene, and the effect of different fuel injection scheme on the overall scramjet combustion efficiency was determined. Based on hydrogenbased supersonic combustor, You et al. [14] had made deep comparison between RAN model and DES model. You et al. [14] stated that the RAN model cannot finely capture the dynamic characteristics of turbulent structures, but it can predict the overall performance of scramjet combustor with no much fidelity loss when compared to the DES model. 


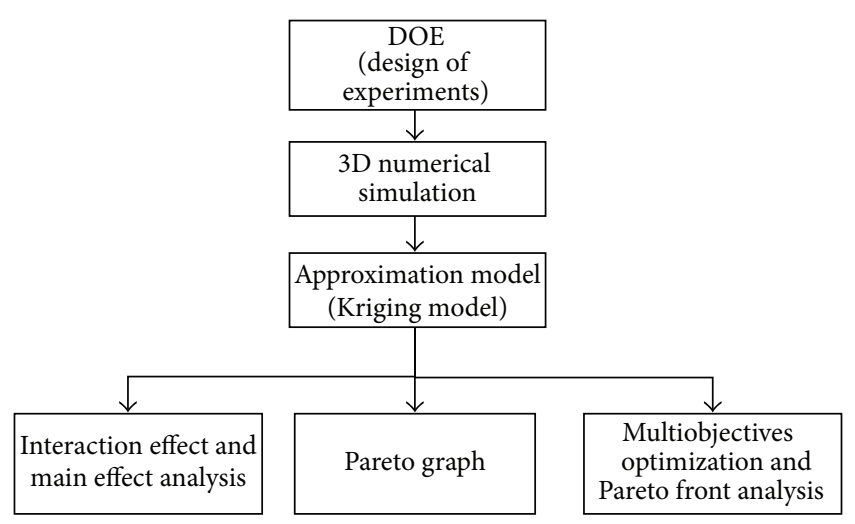

FIgURE 1: The flow chart of parametric study process.

The current paper gives a comprehensive parametric study of a kerosene-based supersonic combustor using 3D numerical simulation method. A 3D kerosene-based scramjet combustor with a recessed cavity was adopted here. The effects of fuel distribution were specially taken into consideration. Figure 1 shows the flow chart for the entire parametric study process. Here, 3D Navier-Stokes equations and SST $k-\omega$ RANS-based turbulence model together with discrete phase model were employed to predict the flow field. It is an effective way to model liquid fuel injection as discrete phase model which has been proved in [9]. A 1-component surrogate model $\left(\mathrm{C}_{12} \mathrm{H}_{24}\right)$ and four-step chemical kinetic model were used to represent typical chemical properties of kerosene. Additionally, DOE (design of experiments) method was adopted to better explore the design space. Fluent software was used to conduct 3D numerical simulation to predict the flow field and then train the sample points. Based on the sample points, Kriging approximation model which can be used to fast evaluate the performance of the supersonic combustor was constructed. The running time of Kriging model is less than one second, which is much less than the time required by direct CFD computation. And this can make multiobjectives optimization study much more practical. The distributed fuel injection scheme was optimized by nondominated sorting genetic algorithm-II (NSGA-II), which is one of the efficient algorithms for optimizing multiobjectives/multivariables problem [10]. And, at last, the results from comprehensive parametric study including main effect analysis, Pareto front analysis, and multiobjectives optimization were presented. There are three objective functions used here to evaluate the combustor performance, namely, the total pressure recovery coefficient, the drag coefficient, and the combustion efficiency, respectively. Up to four parameters were chosen as the design variables, which are the fuel equivalence ratio for four injection ports at four different locations, respectively.

\section{Physical Model}

The scramjet combustor model used here, shown in Figure 2(a), is similar to the model adopted by Yu et al. [5]. It is a plane symmetry combustor. There are totally three sections contained in the combustor. The first section is a nearly constant area (half-expansion angle of $0.5^{\circ}$ ) with length of $0.266 \mathrm{~m}$, connected with expansion section with length of $0.3 \mathrm{~m}$ and half-expansion angle of $1.5^{\circ}$, and the third section is also expansion section with length of $0.336 \mathrm{~m}$ and half-expansion angle of $2.0^{\circ}$. The combustor entrance is $0.0305 \mathrm{~m}$ in height and $0.03 \mathrm{~m}$ in width. A cavity is located at $0.115 \mathrm{~m}$ downstream of the combustor entrance. The cavity is $0.008 \mathrm{~m}$ in height, $0.045 \mathrm{~m}$ in length, and $45^{\circ}$ in aft-wall angle, respectively.

The fuel injection scheme was designed as Figure 2(b). Fuel is injected from the orifice with diameter of $0.4 \mathrm{~mm}$ at four different locations. The fuel injection direction for each orifice is perpendicular to the wall. Every fuel injection orifice is located at the centerline of the top and bottom wall. The distances from the combustor entrance are $0.035 \mathrm{~m}, 0.115 \mathrm{~m}$, $0.155 \mathrm{~m}$, and $0.240 \mathrm{~m}$, respectively, for the first, second, third, and fourth fuel injection orifice. In the current study, the geometry is simplified as $5 \mathrm{~mm}$ long spanwise section, which is equal to the internal distance of fuel injection orifice in [5]. Due to its symmetric characteristics with regard to horizontal center plane, the model was again simplified as top half model shown in Figure 2(c). Here, the usage of half-symmetry model can save lots of computational time.

The operating conditions for the current scramjet combustor are as follows. At the combustor entrance, the Mach number is $\mathrm{Ma}=2.5$, the total pressure is $P_{0}=1.35 \mathrm{MPa}$, and the total temperature is $T_{0}=1720 \mathrm{~K}$. The inflow air is composed of $20 \% \mathrm{O}_{2}, 13.4 \% \mathrm{H}_{2} \mathrm{O}$, and $66.6 \% \mathrm{~N}_{2}$ in mass fraction. Kerosene is injected at room temperature $T=300 \mathrm{~K}$ together with the static pressure of $2.5 \mathrm{MPa}$ for all injection ports.

\section{Methodology}

3.1. Numerical Simulation Method. Here, commercial software, Gambit, is employed to generate high-quality structured grids. In order to avoid inappropriate grid structure for complex configuration, the computational domain, shown in Figure 2(c), is divided into 6 blocks, which are all threedimensional. All blocks are patched together to form the entire mesh. In the vicinity of the wall and fuel injection orifices, the grid is refined, and the space of the first layer grid near the wall (including the upper wall and the cavity wall) is about $1.0 e-5 \mathrm{~m}$. This can make $y^{+}<10$, which has been proved to be able to resolve $3 \mathrm{D}$ supersonic combustor problem well [11]. Thus, the grid has a high capability of resolving power in turbulence problem. The grid is also refined at the location with large gradient of the flow field to enhance the capability of capturing shock wave. The whole mesh consists of about 573,000 cells. The mesh is generated on the right-hand Cartesian coordinates, in which $x$-axis is taken along with the combustor length direction, while $y$-axis and $z$-axis are along with the height and width direction of the combustor, respectively. The origin for the coordinate system is placed at the intersection point between the central line of the bottom wall and the plane of the combustor inlet.

Here, 3D implicit Reynolds-averaged Navier-Stokes (RANS) equations coupled with two-equation SST $k$ - $\omega$ turbulence model and multisteps chemistry set are used to 


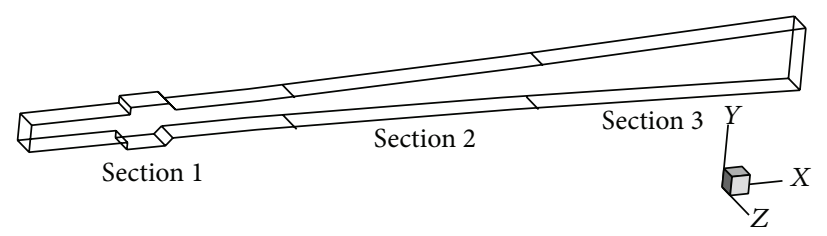

(a) Practical physical model

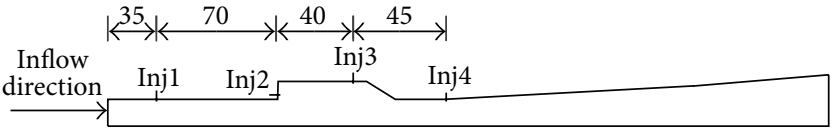

(b) Schematic for fuel injection location (half-symmetry model, units in $\mathrm{mm}$ )

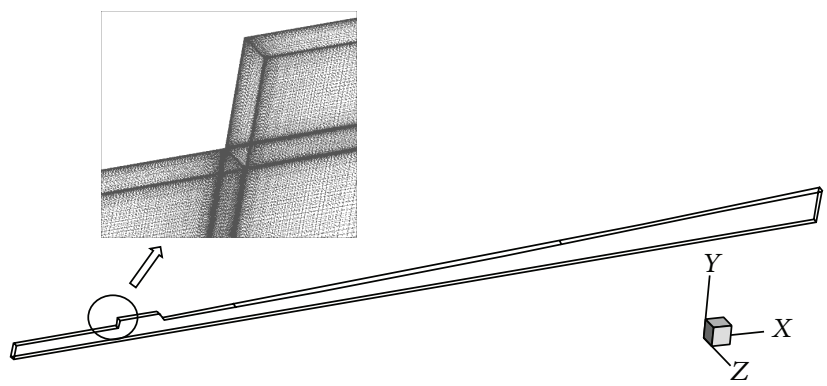

(c) Calculated model and mesh

Figure 2: Physical model and mesh.

predict the flow field of $3 \mathrm{D}$ supersonic combustor. Twoequation SST $k-\omega$ turbulence model computes the nearwall treatment for low-Reynolds number [11]. Because the volumetric fraction of liquid fuel is much less than $10 \%$ under the conditions considered in the current paper, discrete phase model (DPM) is employed here. In discrete phase model, the liquid fuel is assumed to be composed of liquid droplets. In numerical calculation process, the droplets' dynamic characteristics include droplets trajectory and mass/heat exchanging with continuous phase is calculated. This model could decrease computational cost greatly. The liquid fuel injected into the main flow is modelled as discrete phase while the main flow is modelled as continuous phase. The discrete phase is highly coupled with the continuous phase, and steady particle tracking model and dispersion of droplet due to turbulence are both taken into consideration. The Rosin-Rammler diameter distribution method is employed to predict the diameter distribution of fuel droplet, of which the average diameter value is assumed to be equal to $0.025 \mathrm{~mm}$ (the data is selected from [5]). A similar numerical method has been proved by [3] that it can predict the flow field of kerosene-based supersonic combustor well.

3.2. Chemical Kinetics for Kerosene. However, due to the uncertainty in the ingredients of kerosene (the species of kerosene are different from batch to batch) and the complexity of kerosene combustion process, there is a great difficulty in obtaining detailed chemical kinetic mechanism. Meantime, it is unpractical to simulate kerosene combustion process with detailed chemical kinetic mechanism. Fortunately, there are more and more works devoted to finding surrogate model and reduced chemical kinetic model to represent the typical physical and chemical properties of kerosene. This can greatly help to simulate the kerosene combustion process accurately with much less time-consumption [17$20]$. Dagaut $[17,20]$ conducted a comprehensive investigation
TABLe 1: Chemical kinetic mechanism for kerosene combustion [24].

\begin{tabular}{lccc}
\hline Reaction & $A$ & $n$ & $E$ \\
\hline $\mathrm{C}_{n} \mathrm{H}_{m} \rightarrow(n / 2) \mathrm{C}_{2} \mathrm{H}_{4}+(m / 2-n) \mathrm{H}_{2}$ & $2.09 e+17$ & 0 & 24962 \\
$\mathrm{C}_{2} \mathrm{H}_{4}+\mathrm{O}_{2} \rightarrow 2 \mathrm{CO}+2 \mathrm{H}_{2}$ & $5.01 e+14$ & 0 & 25164 \\
$\mathrm{H}_{2}+0.5 \mathrm{O}_{2} \rightarrow \mathrm{H}_{2} \mathrm{O}$ & $3.31 e+13$ & 0 & 20634 \\
$\mathrm{CO}+0.5 \mathrm{O}_{2} \rightarrow \mathrm{CO}_{2}$ & $4.00 e+14$ & 0 & 20131 \\
\hline
\end{tabular}

on the surrogate model for kerosene and he showed that some surrogate model with 1-3 components can represent main properties of kerosene well. Kumaran and Babu [3] used RANS method coupled with discrete phase model to simulate a kerosene-based supersonic combustor. A one-step reaction mechanism was employed and it is proved to be able to predict the pressure distribution characteristics of the flow field well. In this case, kerosene was represented as $\mathrm{C}_{12} \mathrm{H}_{24}$. Zhang et al. [21] carried out a numerical research on a kerosene-based scramjet combustor with 1-component surrogate model $\left(\mathrm{C}_{11} \mathrm{H}_{23}\right)$ and four-step chemical kinetic mechanism. Zhang showed that this chemical model can predict the combustion process well.

Multisteps reaction mechanism used in the current paper is shown as Table 1. Herein, kerosene chemical kinetics are in Arrhenius form, $k=A T^{n} e^{-E / R T}$, and kerosene is modelled as $\mathrm{C}_{12} \mathrm{H}_{24}$ [22]. The mechanism has been evaluated by lots of experimental and numerical results and has been proved to show reasonable accuracy in a relatively broader range [21, 23-25].

3.3. Boundary Conditions. At the combustor entrance, the pressure inlet boundary condition is used where the static pressure, the total pressure, the total temperature, and the species mass fraction are specified. The inflow at the entrance is assumed to be uniform. As for the fuel injection, it is 


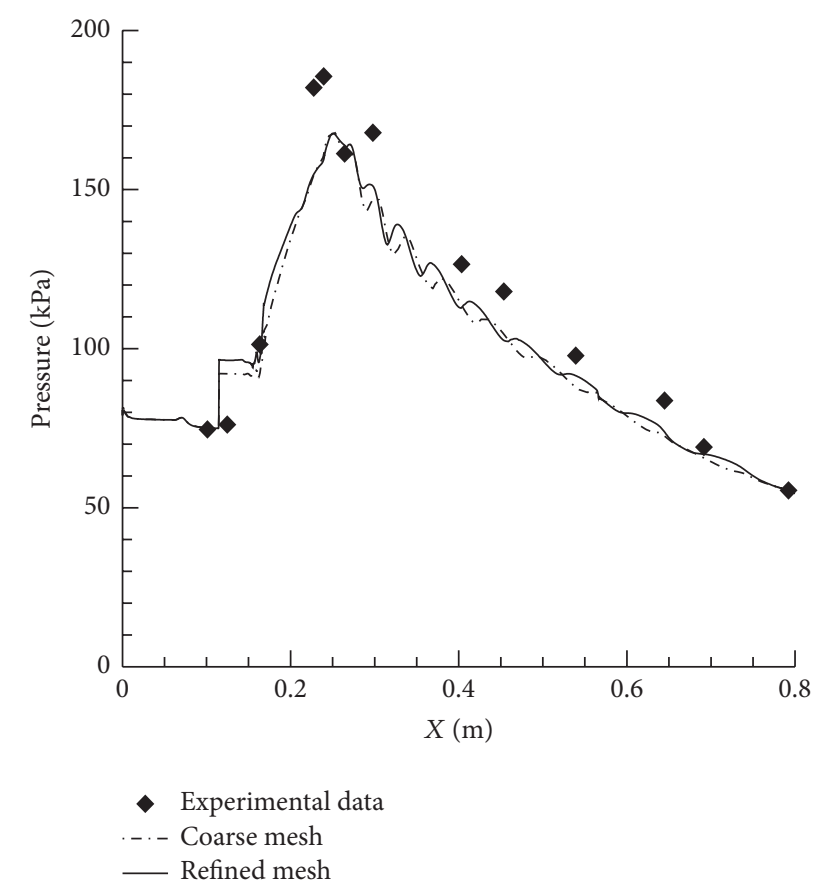

FIGURE 3: Comparison between the predicted data and experimental data (the data shown in this figure is the static pressure distribution along the top wall).

modelled as discrete phase model, where the mass flow rate, the size and location of fuel injection orifice, the fuel temperature, the fuel velocity, and the average diameter of fuel droplet are specified. Here, the fuel mass flow rate is calculated from fuel equivalence ratio. At the combustor exit where the pressure outlet boundary condition is applied, the variables are determined from interior flow field by extrapolation. In addition, no-slip wall boundary condition is applied to all walls. All walls are assumed to be adiabatic requiring the normal derivative of temperature to vanish. Along the horizontal central plane of the combustor, the planar symmetry boundary condition is used.

3.4. Validation of Numerical Simulation Method. In order to validate the accuracy and reliability of the numerical simulation method, the predicted flow field has been compared with experimental data firstly. Here, the experimental data was selected from [5]. And, then, grid independence study was also carried out. Figure 3 shows the comparison between the experimental data and the predicted data based on different grid size level. In Figure 3, the pressure curve represents the static pressure distribution along the centerline of the top wall. Herein, the cell number of coarse mesh is about 573,000 and the refined mesh's cell number is about 825,000.

It can be seen from Figure 3 that the numerical method adopted in this paper can predict the overall trend of the pressure distribution well, but there is still a notable difference at some locations. The maximum difference is about $13.7 \%$ at $x=0.245 \mathrm{~m}$. The difference between the predicted data and the experimental data might be caused by numerical errors. From Figure 3, we can also find that the
TABLE 2: Design space for DOE.

\begin{tabular}{lc}
\hline Parameter $(m)$ & Value \\
\hline$\phi_{1}$ & {$[0.0,0.15,0.30,0.45,0.6]$} \\
$\phi_{2}$ & {$[0.0,0.15,0.30,0.45,0.6]$} \\
$\phi_{3}$ & {$[0.0,0.15,0.30,0.45,0.6]$} \\
$\phi_{4}$ & {$[0.0,0.15,0.30,0.45,0.6]$} \\
& $0.0<\phi_{\text {total }}<0.8$ \\
\hline
\end{tabular}

predicted data between two different grid size levels has slight difference. Thus, it can be concluded that the predicted data is independent of the grid size level when the grid size level is placed within the range of $[573,000,825,000]$. Taking the huge difficulties in the numerical simulation of supersonic combustion into consideration, the numerical simulation method adopted in this paper is acceptable. And, finally, the mesh cell number is fixed at about 573,000 $(900 \times 91 \times 7)$ to save computational cost without too much accuracy loss.

3.5. DOE (Design of Experiments) and Kriging Approximation Model. In recent years, the use of high-fidelity CFD method for analyzing the flow field in supersonic combustor has dramatically increased. In addition, kinds of optimization techniques have been developed to obtain optimal solution [16]. However, the optimization process will iterate at least thousands of iterations before it converges. Thus, it is very difficult to couple high-fidelity CFD directly with optimization algorithm to carry out optimization research due to the huge computational cost of CFD. DOE technique and approximation model can provide a much easier way to alleviate such difficulty.

DOE technique can be used to help better explore design space. In the current study, Optimal Latin Hypercube DOE method [26] is employed to conduct the DOE study. Optimal Latin Hypercube method is a statistical method for generating a sample of plausible collections of parameter values from a multidimensional distribution [26]. It allows many more points and more combinations to be studied for each factor, and experiment points are spread evenly, allowing higher order effects to be captured. Designer has total freedom in selecting the number of designs to run as long as it is greater than the number of factors. Table 2 shows the basic input conditions for DOE study. Here, the fuel equivalence ratios for four different fuel injection orifices were selected as the design variables, and each design variable has five design levels which are $0.0,0.15,0.30,0.45$, and 0.60 , respectively. The variables $\phi_{\text {Inj1 }}, \phi_{\text {Inj2 }}, \phi_{\text {Inj3 }}$, and $\phi_{\text {Inj4 }}$ represent the fuel equivalence ratio for the first, second, third, and fourth injection port, respectively. In order to avoid the thermal choking, the constraint of $0.0<\phi_{\text {total }}<0.8$ is also specified. Through DOE study, we got totally 30 sample points.

Kriging approximation is a type of reduced order model, which has been proved to be able to do well with complexity problem such as multiobjectives/multivariables problem and multipeaks problem $[16,27,28]$. It can save lots of computational time and ultimately make optimization process available. In the current paper, Kriging approximation model 

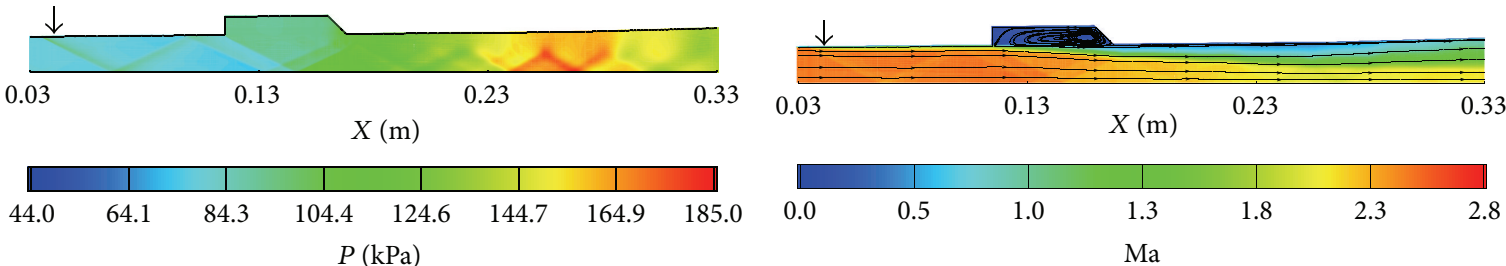

(a) Static pressure contour

(b) Mach number contour and streamlines

Figure 4: Detailed flow field for Case 1.

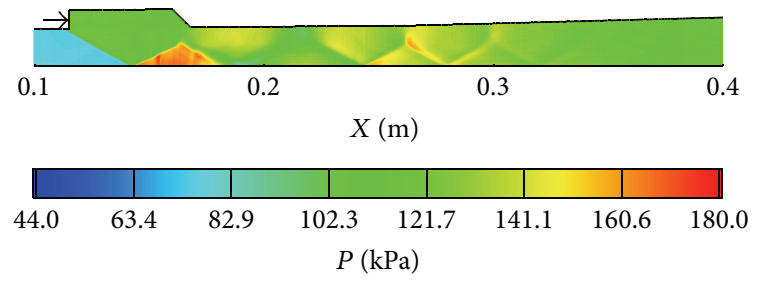

(a) Static pressure contour

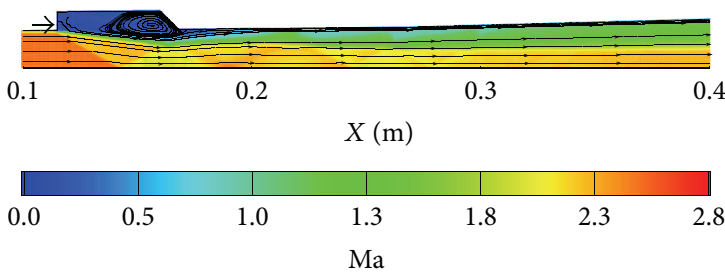

(b) Mach contour and streamlines

FIGURE 5: Detailed flow field for Case 2.

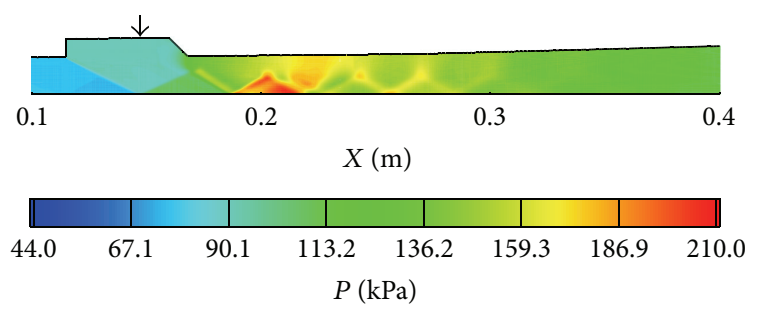

(a) Static pressure contour

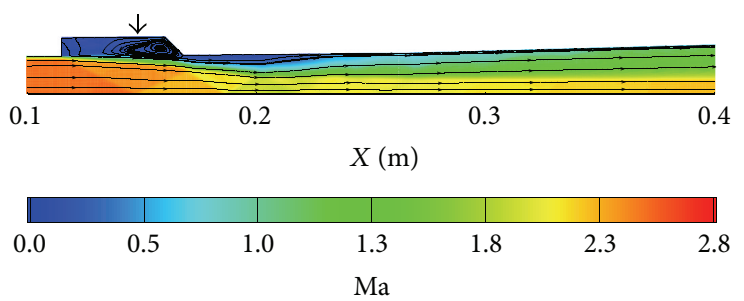

(b) Mach contour and streamlines

Figure 6: Detailed flow field for Case 3.

is used to rebuild the relationships between the design variables and the objective functions.

\section{Results and Discussion}

Three objective functions are considered in the current study, namely, the combustion efficiency, the total pressure recovery coefficient, and the drag coefficient. The combustion efficiency is calculated based on fuel consumption at the outlet plane of the combustor. Hence, it gives an indication of the completeness of combustion process. The combustion efficiency at the outlet plane is given as [29]

$$
\eta_{c}=\frac{\left(\int_{x} 168 /(12 \times 44) \alpha \rho u d A\right)}{\left(\sum_{x} m_{\text {fuel,in }}\right)}
$$

where $\alpha$ is the mass fraction of $\mathrm{CO}_{2}$ and the multiplicative in the numerator accounts for the fact that $12 \mathrm{kmoles}(12 \times 44 \mathrm{~kg})$ of $\mathrm{CO}_{2}$ is produced from the combustion of $1 \mathrm{kmole}(168 \mathrm{~kg})$ of kerosene.
The total pressure coefficient is defined as

$$
\sigma=\frac{P_{0, \text { out }}}{P_{0, \text { in }}},
$$

where, $P_{0 \text {,in }}, P_{0 \text {,out }}$, and $\sigma$ are the mass-averaged total pressure at the combustor entrance, the mass-averaged total pressure at the combustor exit, and the total pressure recovery coefficient, respectively.

The drag coefficient is defined as

$$
C_{D}=\frac{D}{\left(0.5 \rho V^{2}\right)} \text {, }
$$

where $D$ is the viscous drag force within the combustor. Here, the total drag force is calculated as $X$-direction viscous drag. And $0.5 \rho V^{2}$ is the dynamic pressure defined at the combustor entrance.

4.1. Characteristics of Flow Field. Figures 4-7 show the flow field for different fuel injection conditions. In each case, fuel is solely injected from different fuel injection orifice while the fuel equivalence ratios are all kept to be constant as 0.45 

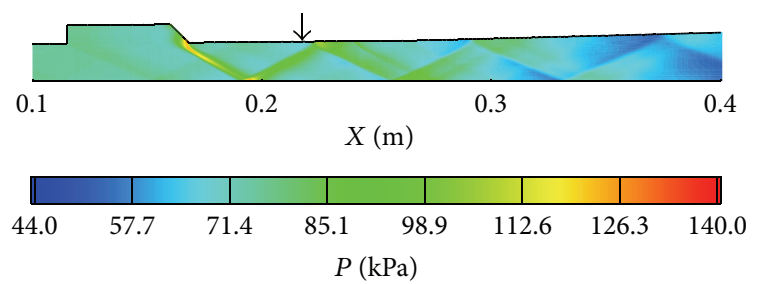

(a) Static pressure contour

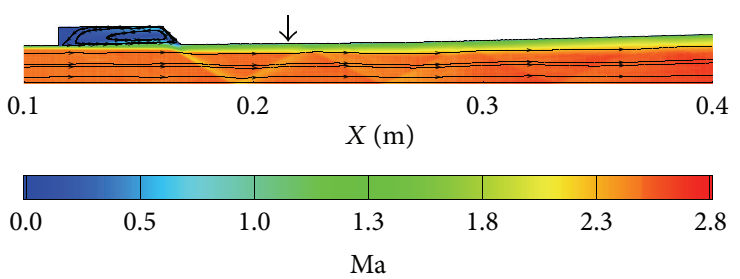

(b) Mach contour and streamlines

Figure 7: Detailed flow field for Case 4.

TABLE 3: Fuel injection conditions for Cases 1-4.

\begin{tabular}{lcccc}
\hline & $\phi_{1}$ & $\phi_{2}$ & $\phi_{3}$ & $\phi_{4}$ \\
\hline Case 1 & 0.45 & 0.0 & 0.0 & 0.0 \\
Case 2 & 0.0 & 0.45 & 0.0 & 0.0 \\
Case 3 & 0.0 & 0.0 & 0.45 & 0.0 \\
Case 4 & 0.0 & 0.0 & 0.0 & 0.45 \\
\hline
\end{tabular}

to understand the influence of the fuel injection location on the overall performance. The arrow shown in Figures 4-7 indicates the fuel injection location, and all of the contour planes are located at $z=0$ plane of the combustor. The fuel injection conditions for four cases are shown in Table 3.

Figure 4 shows the detailed flow field for Case 1. It can be seen from Figure 4(a) that an obvious oblique shock formed at the first fuel injection orifice, and then it was followed by a long shock train. The main flow is supersonic except the flow field within the cavity and some shock/boundary layer interaction area. The reversed flow in the cavity, depicted in Figure 4(b), can help to keep the flame stable. At $x=0.26 \mathrm{~m}$, a strong oblique shock wave train is formed, which may be caused by a great amount of heat release in this location and the oblique shock wave/boundary layer interaction. Obviously, there is a peak value of static pressure with about $185 \mathrm{kPa}$ at the location around $x=0.26 \mathrm{~m}$.

Figure 5 shows the detailed flow field for Case 2. For this situation, fuel is injected from the leading wall of the cavity. And the injection direction is parallel to the main stream direction. Thus, due to the fact that no disturbance is placed on the flow field ahead of the cavity, the flow field of the combustor section ahead of the cavity is very simple and almost tends to be uniform, which can be seen in Figure 5(a). There is also an oblique shock wave that starts from the leading edge of the cavity. When compared to Case 1 , the maximum static pressure for Case 2 is a little smaller (about $180 \mathrm{kPa}$ ). A remarkable recirculation flow exists in the cavity where the velocity is very low. This helps to keep flame holding.

Figure 6 shows the detailed flow field for Case 3. For this case, fuel is injected from the bottom wall of the cavity and the injection direction is perpendicular to the main stream direction. Similar to Case 2, the flow field of the combustor section ahead of the cavity is still simple and tends to be uniform. A remarkable shock train is formed after the leading edge of the cavity, which can be seen in Figure 6(a). From Figure 6(b), we can find that the main flow is supersonic. However, there is still a remarkable low velocity area around

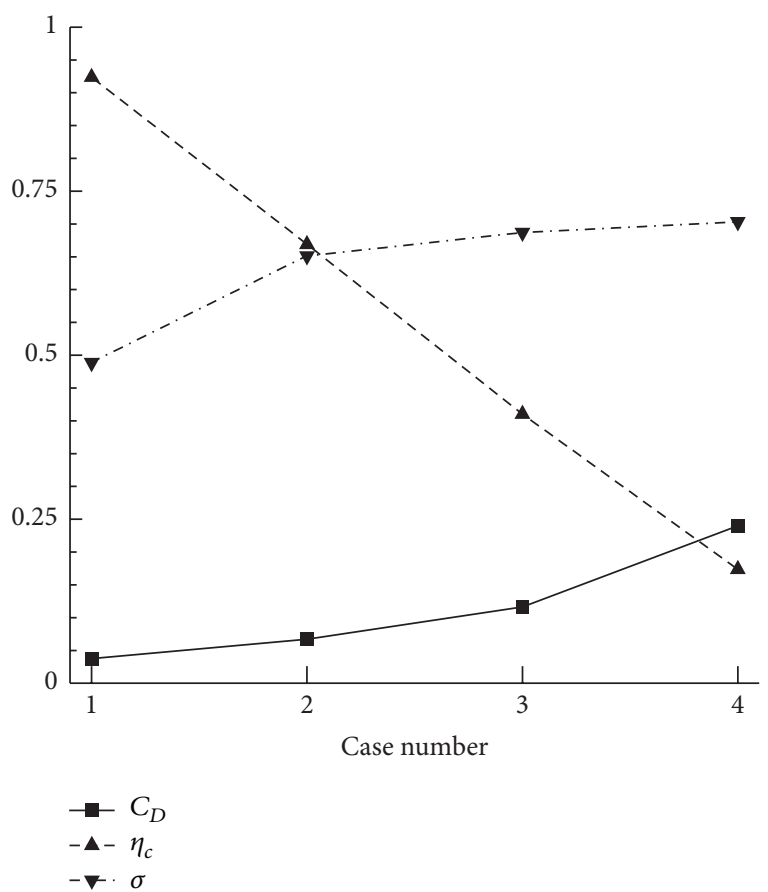

Figure 8: Effects of the fuel injection location on the overall performance.

the location of $x=0.2 \mathrm{~m}$. Accordingly, the location of $x=$ $0.2 \mathrm{~m}$ corresponds to the location where the oblique shock wave strongly interacted with boundary layer, which can be seen in Figure 6(a). The max pressure $(210 \mathrm{kPa})$ in Case 3 is much higher than that of both Cases 1 and 2 .

Figure 7 shows the detailed flow field for Case 4. For this situation, fuel is vertically injected from the upper wall. From Figure 7(a), we can find that the main flow is supersonic except the cavity area. It can be seen from Figure 7(b) that the low velocity area is much smaller when compared to Cases 13. This indicates that the heat release level is low and fuel injected into the combustor has no much time to completely go through the process of evaporation, mixing with air and combustion before fuel escape from the combustor exit. Accordingly, the maximum static pressure in this case is relatively lower and its maximum value is about $140 \mathrm{kPa}$ due to much lower level of heat release.

Figure 8 shows the effect of fuel injection location on the overall performance of the combustor. From Figure 8, we can 
find that when keeping the fuel equivalence ratio constant, the fuel injection location places a great influence on three objective functions. With the increase of the distance from the injector orifice to the combustor inlet, the total pressure recovery coefficient and drag coefficient increase with different increments while the combustion efficiency decreases gradually. Simulation results also show that better overall performance can be achieved in terms of the combustion efficiency and the drag coefficient as fuel is injected at the upstream fuel injector, while the combustor will get worse performance in terms of the total pressure recovery coefficient as fuel is injected at the upstream fuel injector. When comparing Case 4 with Case 1, the combustion efficiency decreases about $77.3 \%$, the total pressure recovery coefficient increases about $46.9 \%$ and the drag coefficient increases by 0.2 .

4.2. Interaction Effect Analysis and Main Effect Analysis. In this section, we present a comprehensive study on interaction effects of the design variables on the objective functions. Interaction effect shows the main effect of a selected factor on a response at each level of another factor.

In interaction graph, lines that are parallel indicate that two factors have no interaction effect on the response (the less parallel the lines, the greater the interaction). Herein, we check the interaction effect between every two design variables, which can be seen in Figures 9-11. The interaction effect was analyzed based on regression analysis method [30].

There are different interaction effects for different objective functions. Two lines in Figure 10(c) are almost parallel to each other and this indicates that there is slight interaction effect of $\phi_{1}$ and $\phi_{4}$ for the drag coefficient. Except for $\phi_{1}$ and $\phi_{4}$, remarkable interaction effects exist between other design variables for the drag coefficient, which can be seen in Figure 10. Such remarkable interaction effects indicate that reasonably fuel injection scheme can decrease the drag coefficient.

When compared with the drag coefficient, Figures 9 and 11 present much unapparent interaction effect of the design variables for the response of the combustion efficiency and the total pressure recovery coefficient. As for the response of the combustion efficiency and the total pressure recovery coefficient, there is no remarkable interaction effect of the design variables except for $\phi_{3}$ and $\phi_{4}$.

It is worth noting that interaction effect between $\phi_{1}$ and $\phi_{4}$ for three objective functions considered in this paper is negligible. This indicates that $\phi_{1}$ and $\phi_{4}$ are almost independent of each other. This may be caused by long distance between the first and fourth fuel injection orifice.

Since there is no remarkable interaction effect of the design variables for the response of the combustion efficiency and the total pressure recovery coefficient, we give a further investigation on the main effects of the design variable on the objective functions, which can be seen in Figure 12. Herein, the main effect is the effect of one of the independent design variables on the objective functions, ignoring the effects of all other independent variables.

Due to the strong interaction effect of the design variable for the response of the drag coefficient, the main effect for the drag coefficient has no significance and its analysis results are not presented here. From Figure 12(a), we can find that $\phi_{1}$, $\phi_{2}$, and $\phi_{3}$ have strong impact on the combustion efficiency, while $\phi_{4}$ have relatively less impact. As for the total pressure recovery coefficient, it is impacted by $\phi_{1}$ greatly. However, $\phi_{3}$ and $\phi_{4}$ have much less impact on the total pressure recovery coefficient.

4.3. Pareto Graph. Pareto graph is a graph that shows the relative effects of the factors on a response as determined by the data set's regression analysis. It is an ordered bar chart that displays the effects of each factor on a selected response [30]. From Pareto graph, we can find the contribution of each design variable to the objective functions, which can be seen in Figure 13.

Before conducting regression analysis, the input data are firstly scaled to range from -1 to 1 and least squares fit is performed on this data. The scaling is performed so that the contributions can be compared more fairly.

It can be concluded from Figure 13(a) that $\phi_{4}, \phi_{2}$, and $\phi_{3}$ devote more than $20 \%$ negative contribution to the combustion efficiency. This means that the combustion efficiency always decreases with increase of $\phi_{4}, \phi_{2}$, and $\phi_{3}$, respectively. However, interaction effect of $\phi_{3}-\phi_{4}$ has nearly $10 \%$ positive effect on the combustion efficiency, and second order of $\phi_{1}$ has about 7\% positive effect. From Figure 13(b), we can find that $\phi_{1}$ has the most negative effect on the drag coefficient (about $-30 \%$ ), and interaction effects of $\phi_{1}-\phi_{3}$ and $\phi_{2}-\phi_{4}$ have the most positive effect on the drag coefficient (about $12 \%$ and $11 \%$, resp.), while interaction effect of $\phi_{1}-\phi_{4}$ has the least effect on the drag coefficient. From Figure 13(c), we can find that $\phi_{1}$, $\phi_{2}, \phi_{3}$, and $\phi_{4}$ have the most negative effect on the total pressure recovery coefficient $(-31 \%,-21 \%,-16 \%$, and -10 , resp.). The remaining interaction effect terms contribute less than $5 \%$ effect on the total pressure recovery coefficient, which is consistent with the results from interaction effect analysis.

\subsection{Multiobjectives Optimization and Pareto Front Analysis.} In order to comprehensively understand the relationship between the objective functions, multiobjectives optimization has been carried out in the current paper. And Pareto front was also obtained from multiobjectives optimization process, which is depicted in Figure 14. Herein, DOE technique and Kriging approximation model together with nondominated sorting genetic algorithm-II (NSGA-II) are employed to carry out the multiobjectives optimization research.

Figure 14(a) illustrates the relationship between the combustion efficiency and the total pressure recovery coefficient. The optimal combustion efficiency increases with the increase of the total pressure recovery coefficient initially, and then it decreases with the increase of the total pressure recovery coefficient. This can be concluded that the combustion efficiency and the total pressure recovery coefficient have their own optimal value, but they cannot reach the optimal solution at the same time. However, from Figure 14(b), it is clearly observed that the optimal drag coefficient decreases with the decrease of the total pressure recovery coefficient. 

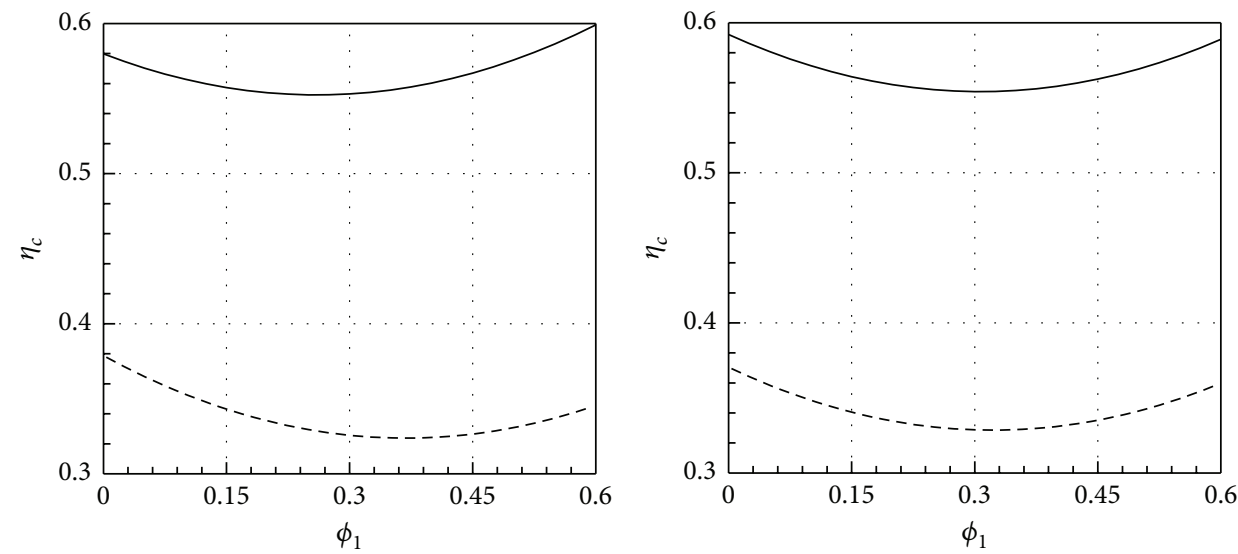

$-\phi_{2}=0.2$

$-\phi_{3}=0.2$

- - $\phi_{2}=0.5$

- - $\phi_{3}=0.5$

(a) $\phi_{1}$ versus $\phi_{2}$

(b) $\phi_{1}$ versus $\phi_{3}$
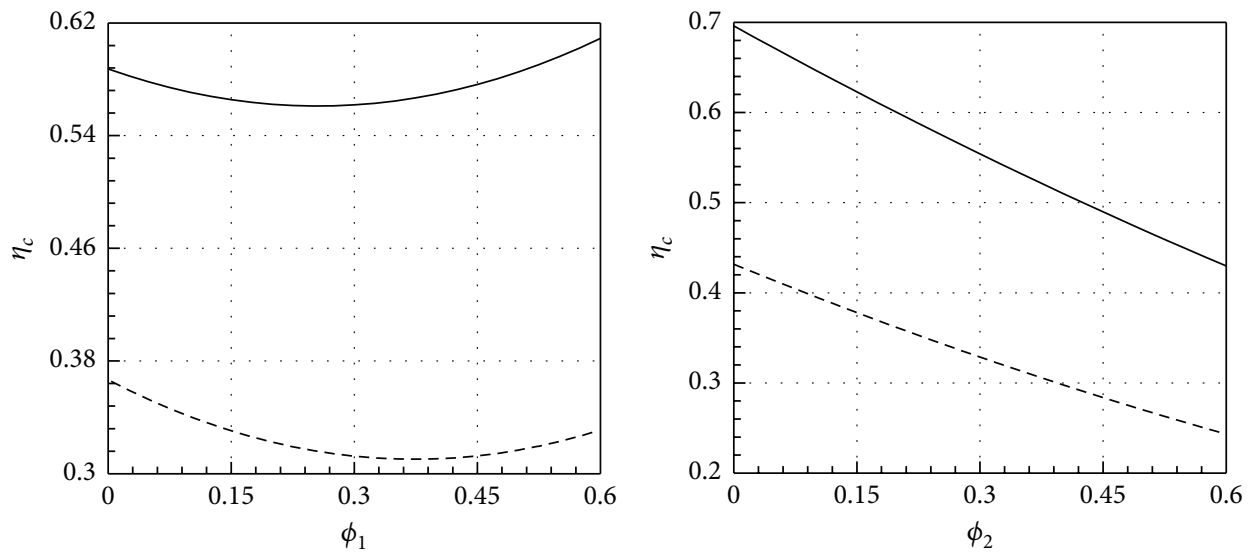

$-\phi_{4}=0.2$

$-\phi_{3}=0.2$

- - $\phi_{4}=0.5$

$--\phi_{3}=0.5$

(c) $\phi_{1}$ versus $\phi_{4}$
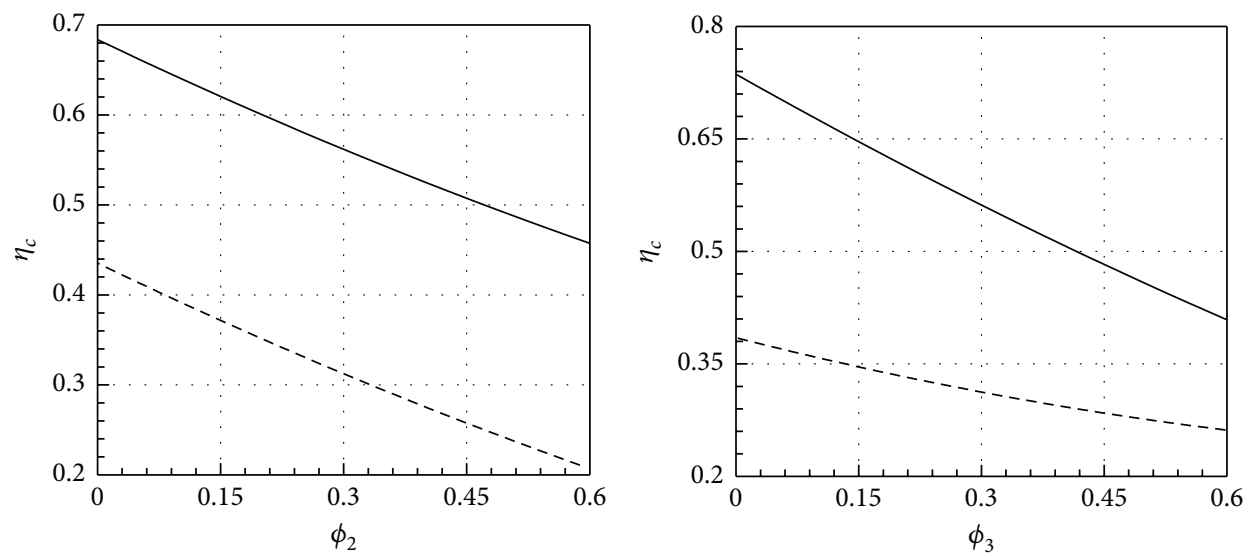

$\phi_{4}=0.2$

- - $\phi_{4}=0.5$

$$
\begin{aligned}
\phi_{4} & =0.2 \\
---\phi_{4} & =0.5
\end{aligned}
$$

(e) $\phi_{2}$ versus $\phi_{4}$

(f) $\phi_{3}$ versus $\phi_{4}$

Figure 9: Interaction effects of the design variables on the combustion efficiency. 

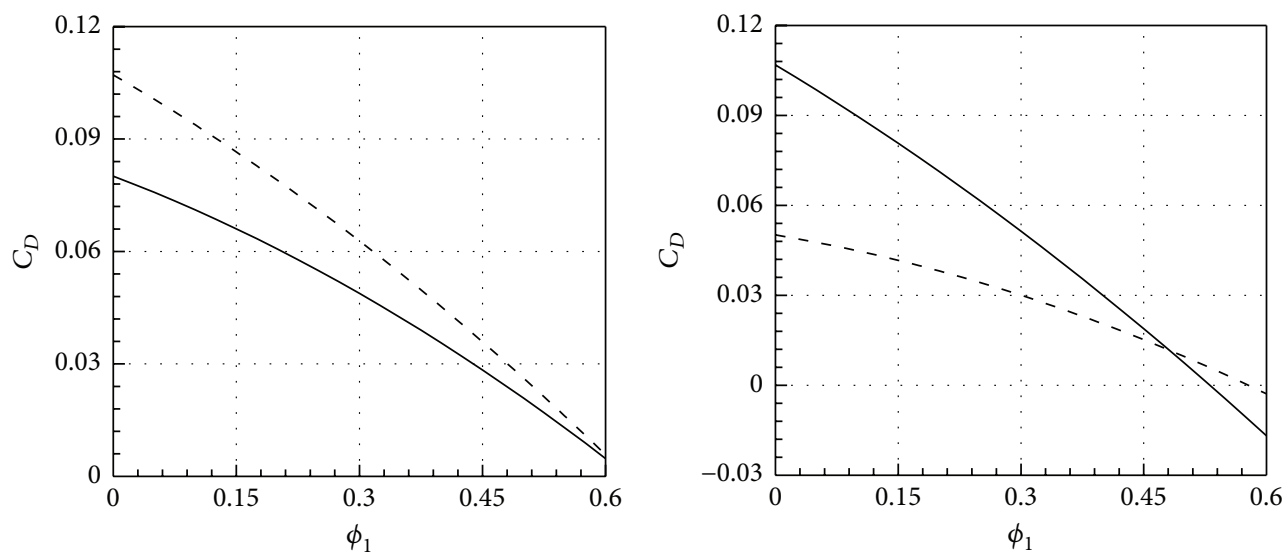

$$
\begin{aligned}
-\phi_{2} & =0.2 \\
---\phi_{2} & =0.5
\end{aligned}
$$

(a) $\phi_{1}$ versus $\phi_{2}$

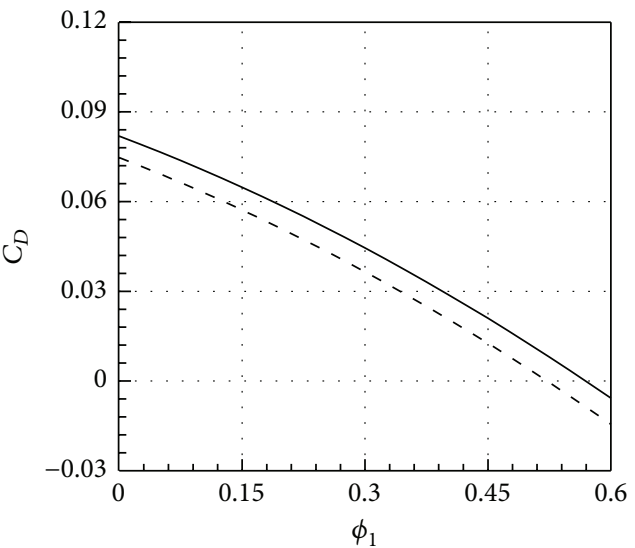

$$
-\phi_{4}=0.2
$$$$
\text { - - } \phi_{4}=0.5
$$

(c) $\phi_{1}$ versus $\phi_{4}$

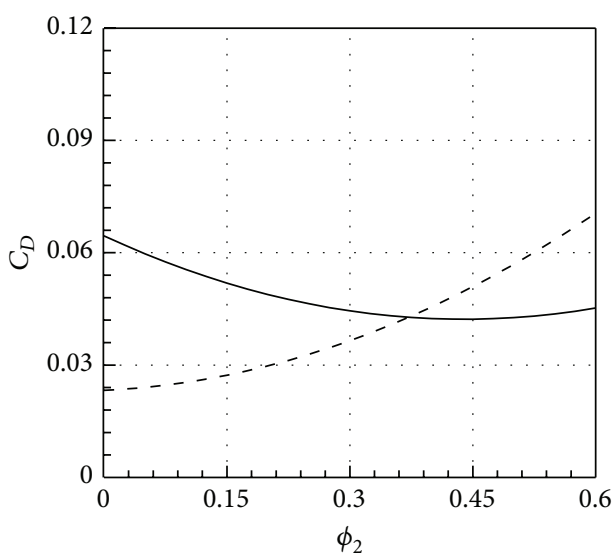

$-\phi_{4}=0.2$

$--\phi_{4}=0.5$

(e) $\phi_{2}$ versus $\phi_{4}$ $-\phi_{3}=0.2$

$--\phi_{3}=0.5$

(b) $\phi_{1}$ versus $\phi_{3}$

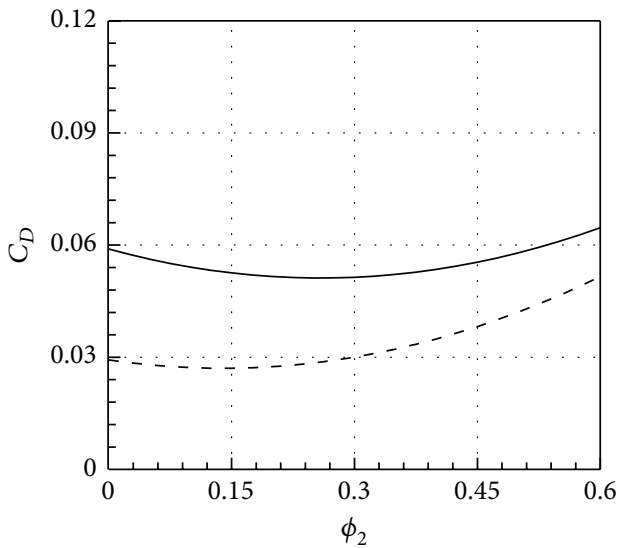

$-\phi_{3}=0.2$

$--\phi_{3}=0.5$

(d) $\phi_{2}$ versus $\phi_{3}$

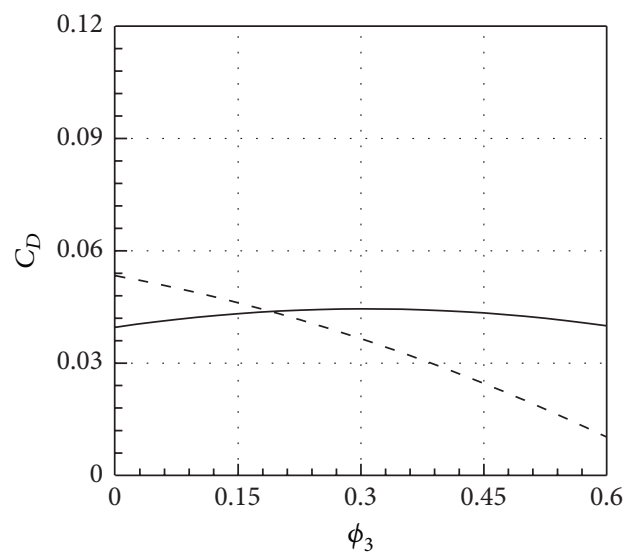

$-\phi_{4}=0.2$

(f) $\phi_{3}$ versus $\phi_{4}$

FIGURE 10: Interaction effects of the design variables on the drag coefficient. 

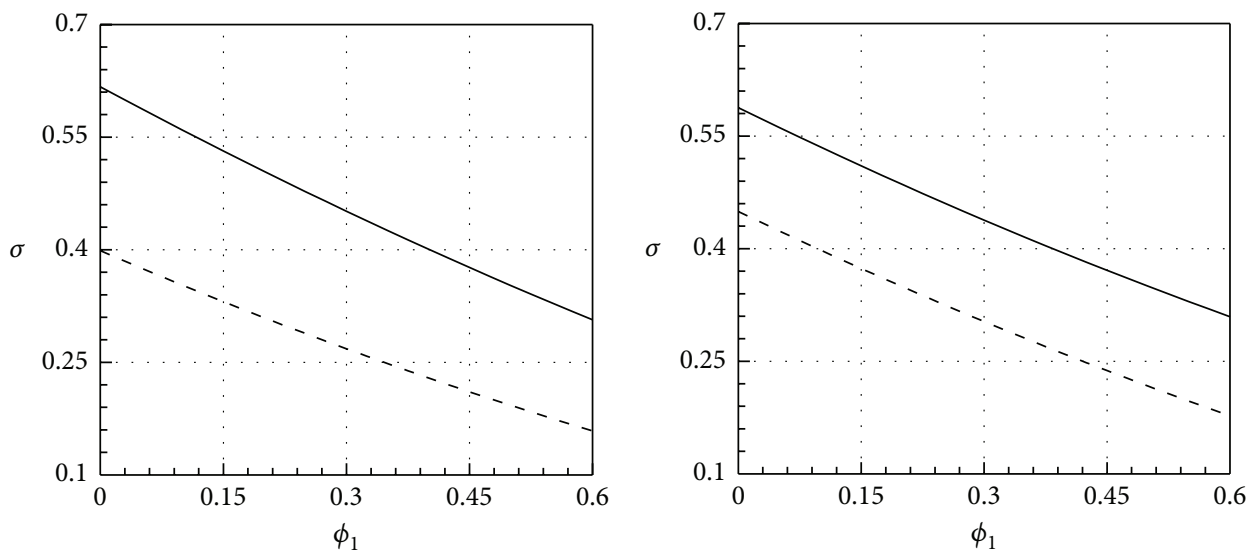

$-\phi_{2}=0.2$

- - $\phi_{2}=0.5$

$-\phi_{3}=0.2$

- - $\phi_{3}=0.5$

(a) $\phi_{1}$ versus $\phi_{2}$

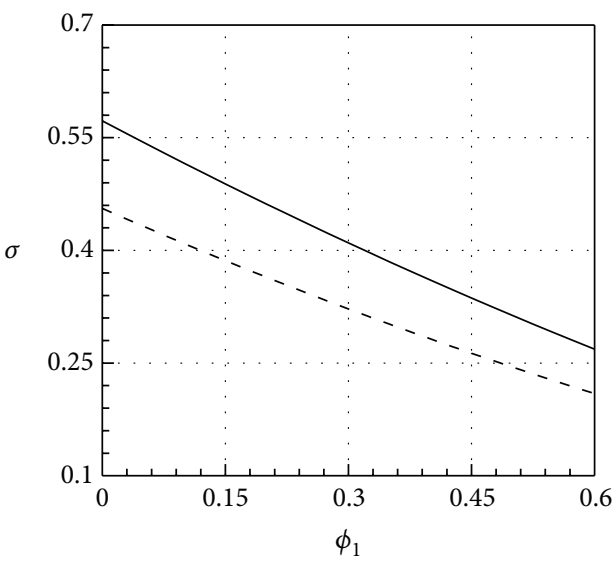

(b) $\phi_{1}$ versus $\phi_{3}$

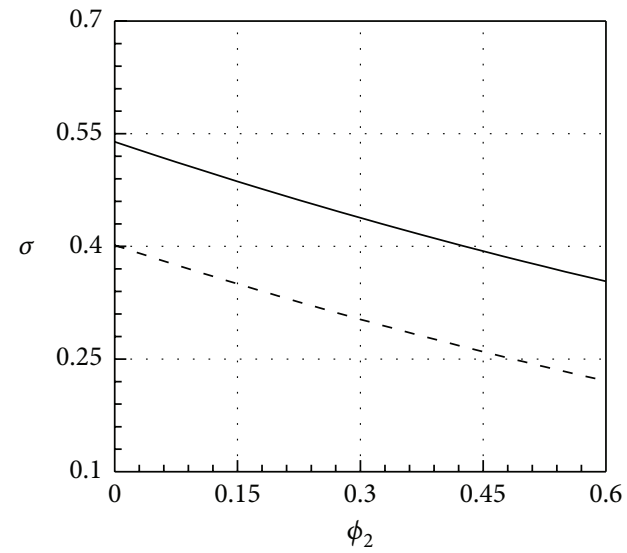

$-\phi_{4}=0.2$

$--\phi_{4}=0.5$

$-\phi_{3}=0.2$

$---\phi_{3}=0.5$

(c) $\phi_{1}$ versus $\phi_{4}$

(d) $\phi_{2}$ versus $\phi_{3}$
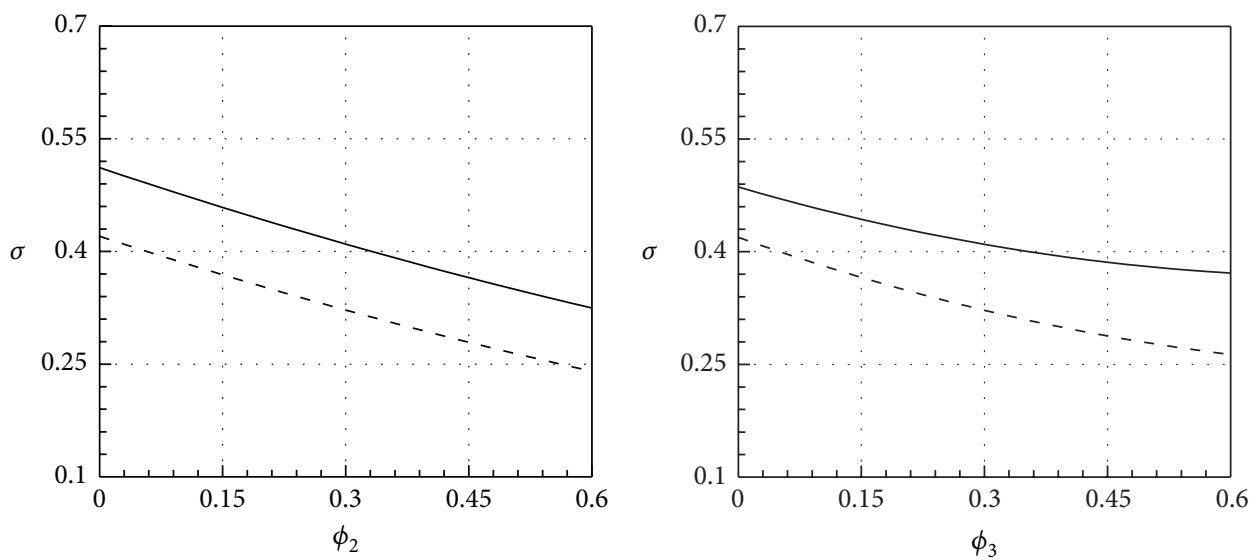

$-\phi_{4}=0.2$

- - $\phi_{4}=0.5$

$-\phi_{4}=0.2$

- - $\phi_{4}=0.5$

(e) $\phi_{2}$ versus $\phi_{4}$

(f) $\phi_{3}$ versus $\phi_{4}$

FIGURE 11: Interaction effects of the design variables on the total pressure recovery coefficient. 


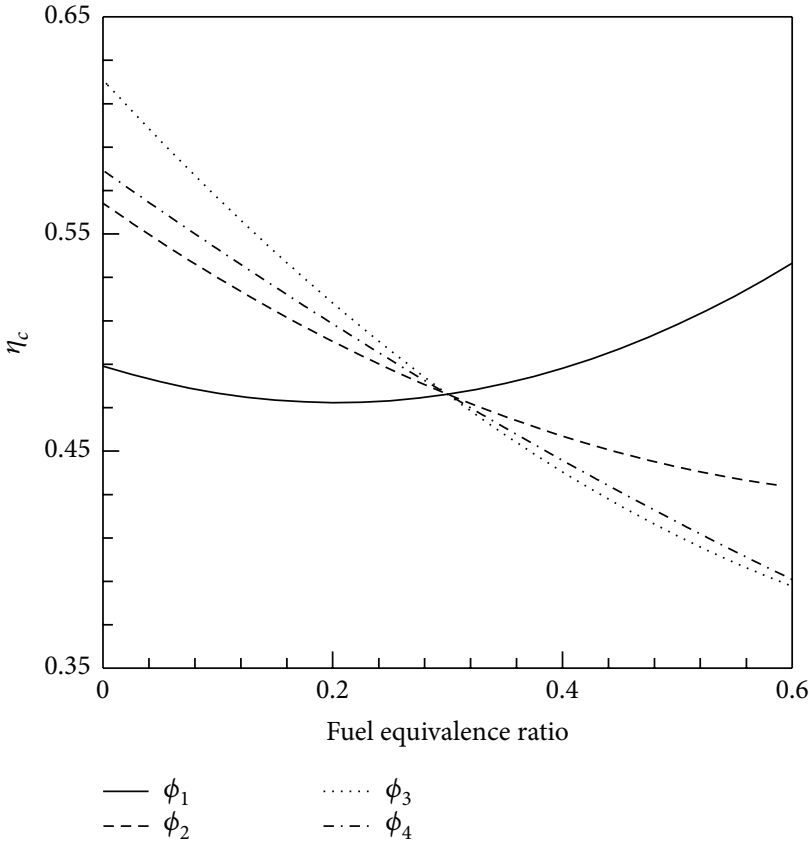

(a) $\eta_{c}$ versus the design variables

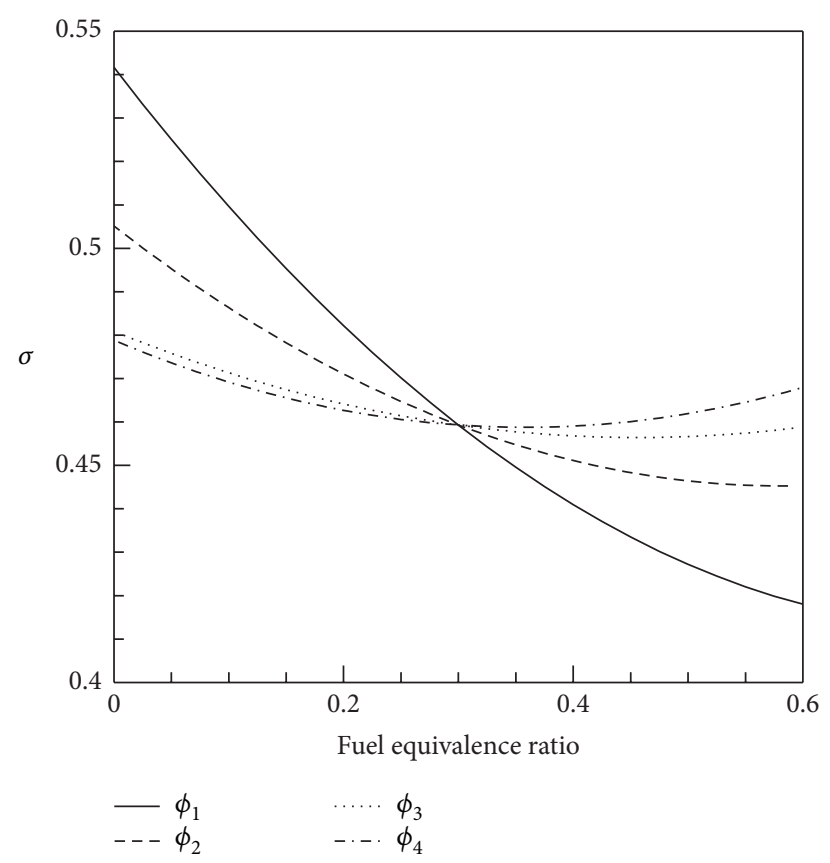

(b) $\sigma$ versus the design variables

FIGURE 12: Main effects of the design variables on the objective functions.

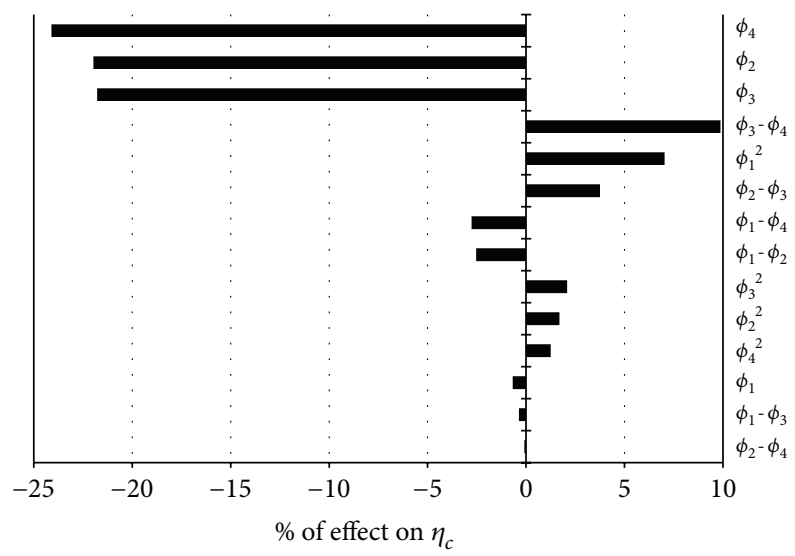

(a) The relative effects of fuel injections on combustion efficiency

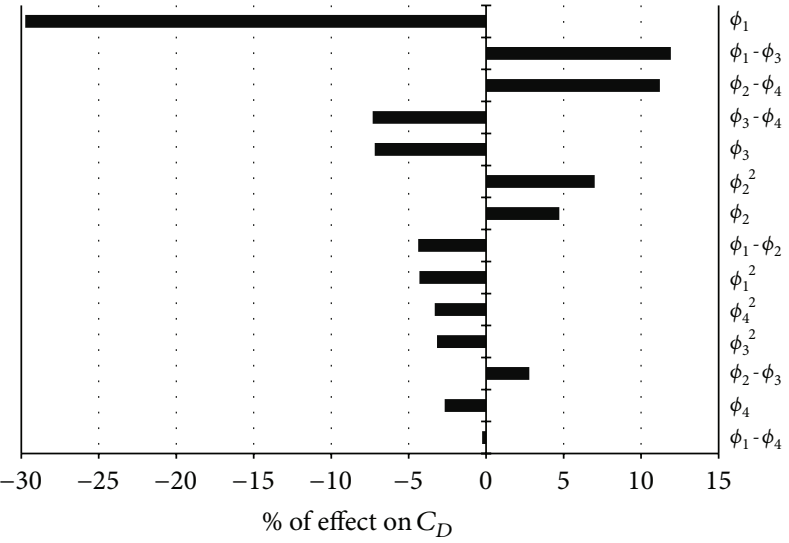

(b) The relative effects of fuel injections on drag coefficient

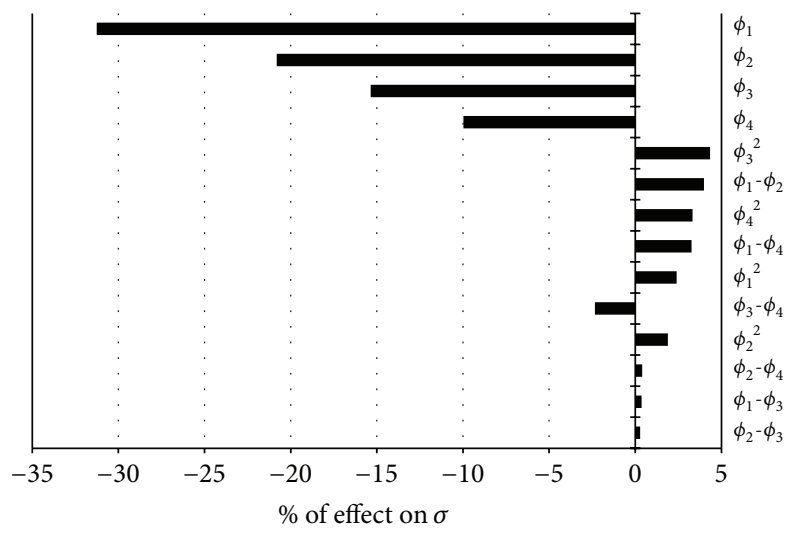

(c) The relative effects of fuel injections on total pressure recovery coefficient

FIGURE 13: Pareto graph for the objective functions. 


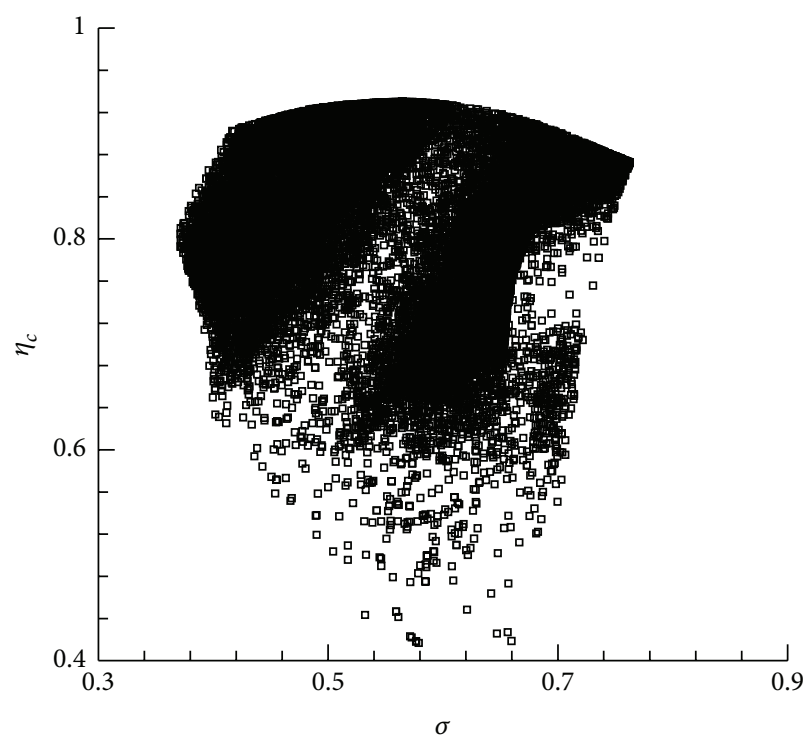

(a) $\eta_{c}$ versus $\sigma$

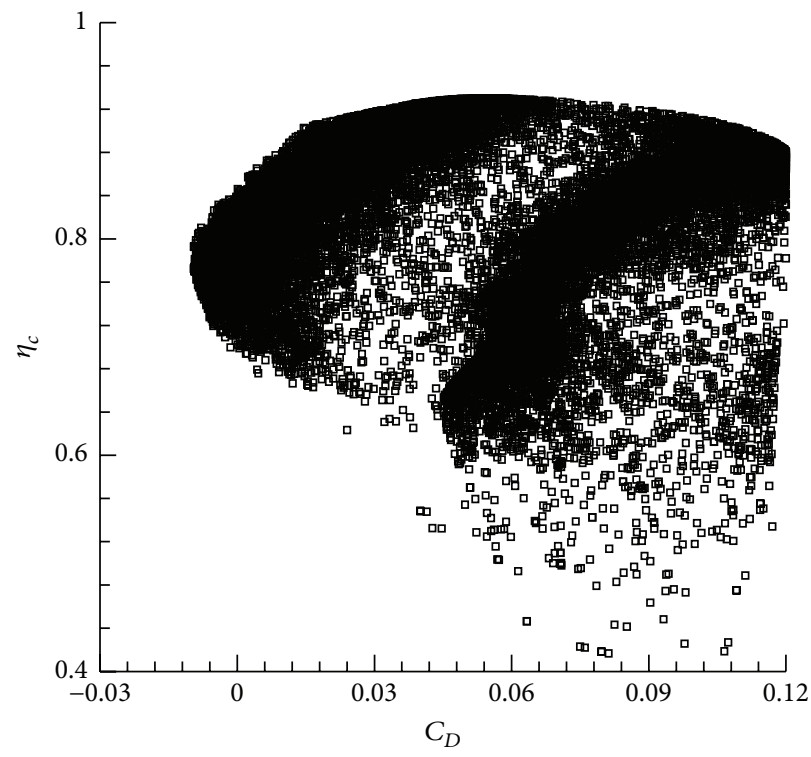

(c) $\eta_{c}$ versus $C_{D}$

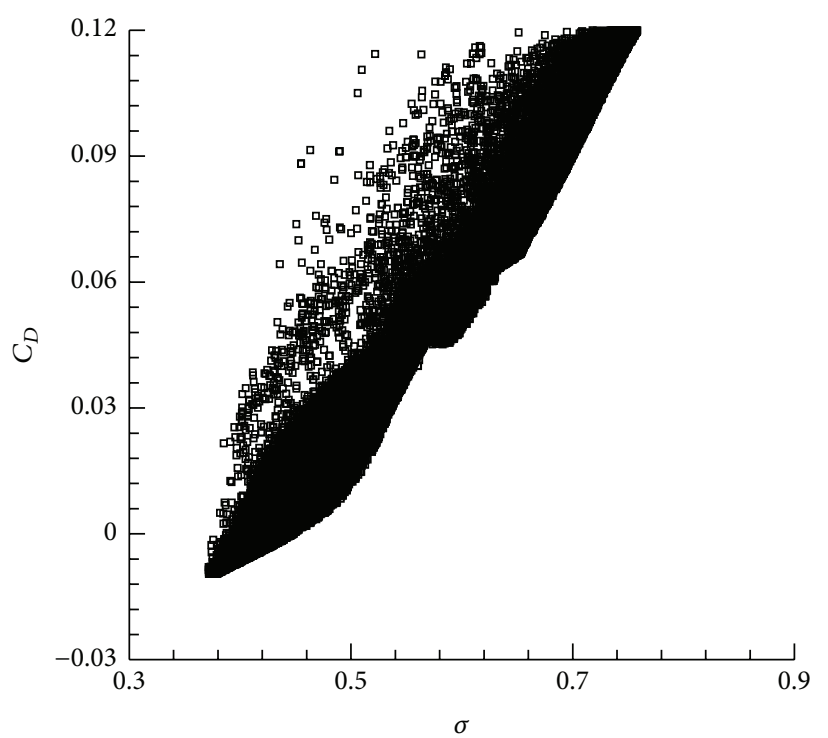

(b) $C_{D}$ versus $\sigma$

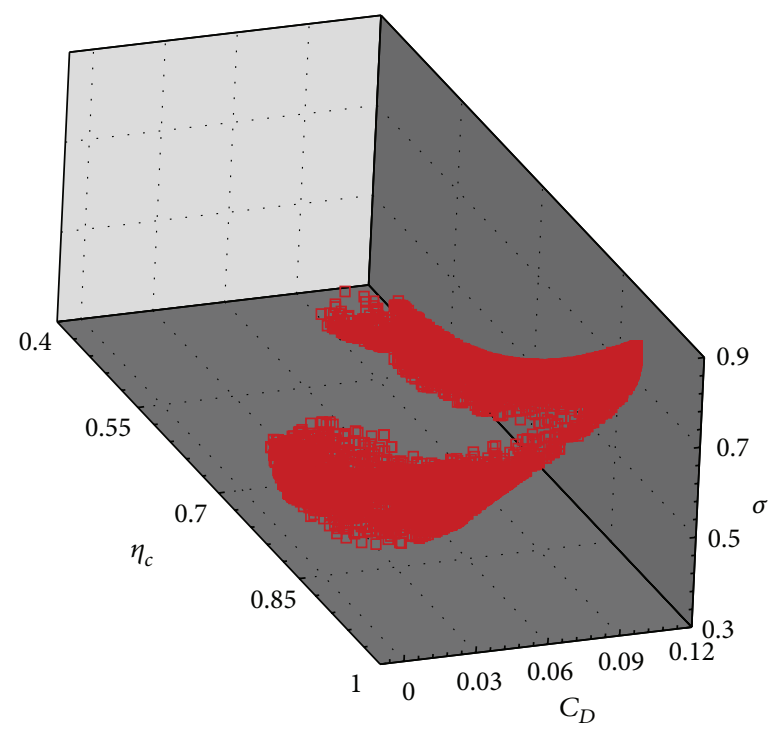

(d) $\eta_{c}$ versus $C_{D}$ versus $\sigma$

FIgURE 14: Pareto front for the objective functions.

And there are also two optimal values for the drag coefficient and the total pressure recovery coefficient, respectively.

From the relationship between the combustion efficiency and the drag coefficient, we can find that there are also two optimal values for the combustion efficiency and the drag coefficient, respectively. Thus, they also cannot reach the optimal value at the same time (see Figure 14(c)).

Finally, a Pareto front for three objectives is plotted in Figure 14(d). It can be easily observed that the potential optimal values for three objective functions conflict with each other. This implies that any objective function reaches the optimal value will lead to the performance loss for the other two objectives. Thus, there must be a tradeoff among three objective functions.

\section{Conclusions}

Based on the agreement of the numerical results and the experimental data, a comprehensive parametric study of fuel distribution effects on the overall performance of a $3 \mathrm{D}$ kerosene-based supersonic combustor has been carried out. Some data mining methods including design of experiments, regression analysis, Kriging approximation model, and multivariables/multiobjectives optimization methods were employed to quantificationally check interaction effect, main effect, and Pareto front.

Both of the fuel injection location and fuel equivalence ratio have great influence on three objective functions considered in this paper. Through carefully tuning the fuel 
distribution, the performance of scramjet combustor can be adjusted flexibly. However, due to remarkable interaction effects among the design variables, this performance adjustment process would be very complicated. Additionally, three objective functions always conflict with each other, so there must be a tradeoff among three objective functions. The results from this paper could give some guidance for scramjet engine design or scramjet control system design.

\section{Nomenclature}

$\begin{array}{ll}k: & \text { Rate constant of chemical reaction } \\ A: & \text { Preexponential factor in Arrhenius } \\ & \text { equation } \\ E: & \text { Activation energy } \\ R: & \text { Universal gas constant } \\ \phi_{1}: & \text { Fuel equivalence ratio for the first fuel } \\ & \text { injection orifice } \\ \phi_{2}: & \text { Fuel equivalence ratio for the second fuel } \\ & \text { injection orifice } \\ \phi_{3}: & \text { Fuel equivalence ratio for the third fuel } \\ & \text { injection orifice } \\ \phi_{4}: & \text { Fuel equivalence ratio for the fourth fuel } \\ & \text { injection orifice } \\ \phi_{\text {total }}: & \phi_{1}+\phi_{2}+\phi_{3}+\phi_{4} \\ \eta_{c}: & \text { Combustion efficiency } \\ \sigma: & \text { Total pressure recovery coefficient } \\ C_{D}: & \text { Drag coefficient. }\end{array}$

\section{Competing Interests}

The authors declare that they have no competing interests.

\section{Acknowledgments}

This research work is supported by the National Natural Science Foundation of China (no. 11272344).

\section{References}

[1] M. Kodera, S. Tomioka, and T. Kanda, "Mach 6 test of a scramjet engine with boundary-layer bleeding and two-staged fuel injection," Tech. Rep. NASA/AIAA-2003-7049, NASA, 2003.

[2] P. Manna, M. Dharavath, P. K. Sinha, and D. Chakraborty, "Optimization of a flight-worthy scramjet combustor through CFD," Aerospace Science and Technology, vol. 27, no. 1, pp. 138146, 2013.

[3] K. Kumaran and V. Babu, "Mixing and combustion characteristics of kerosene in a model supersonic combustor," Journal of Propulsion and Power, vol. 25, no. 3, pp. 583-592, 2009.

[4] X. Y. Wu, X. S. Li, M. Ding, W. D. Liu, and Z. G. Wang, "Experimental study on effects of fuel injection on scramjet combustor performance," Chinese Journal of Aeronautics, vol. 20, no. 6, pp. 488-494, 2007.

[5] G. Yu, J. G. Li, X. Y. Chang, L. H. Chen, and C. J. Sung, "Investigation of kerosene combustion characteristics with pilot hydrogen in model supersonic combustors," Journal of Propulsion and Power, vol. 17, no. 6, pp. 1263-1272, 2001.

[6] X. Fan, G. Yu, J. Li, X. Zhang, and C.-J. Sung, "Investigation of vaporized kerosene injection and combustion in a supersonic model combustor," Journal of Propulsion and Power, vol. 22, no. 1, pp. 103-110, 2006.

[7] M. Ali and A. K. M. S. Islam, "Study on main flow and fuel injector configurations for Scramjet applications," International Journal of Heat and Mass Transfer, vol. 49, no. 19-20, pp. 36343644, 2006.

[8] N. Wang, J. Zhou, Y. Pan, and H. Wang, "Experimental investigation on flow patterns of RP-3 kerosene under sub-critical and supercritical pressures," Acta Astronautica, vol. 94, no. 2, pp. 834-842, 2014.

[9] K. Kumaran, P. R. Behera, and V. Babu, "Numerical investigation of the supersonic combustion of kerosene in a strut-based combustor," Journal of Propulsion and Power, vol. 26, no. 5, pp. 1084-1091, 2010.

[10] K. Deb, A. Pratap, S. Agarwal, and T. Meyarivan, "A fast and elitist multiobjective genetic algorithm: NSGA-II," IEEE Transactions on Evolutionary Computation, vol. 6, no. 2, pp. 182197, 2002.

[11] G. Choubey and K. M. Pandey, "Effect of variation of angle of attack on the performance of two-strut scramjet combustor," International Journal of Hydrogen Energy, vol. 41, no. 26, pp. 11455-11470, 2016.

[12] H. B. Ebrahimi, D. V. Gaitonde, and F. J. Malo-Molina, "Parametric study of 3-D hydrocarbon scramjet engine with cavity," in Proceedings of the 45th AIAA Aerospace Sciences Meeting and Exhibit, AIAA 2007-645, pp. 7773-7787, Reno, Nev, USA, January 2007.

[13] K. M. Pandey and Sivasakthivel, "CFD analysis of mixing and combustion of a scramjet combustor with a planer strut injector," International of Environmental Science and Development, vol. 2, no. 2, pp. 102-108, 2011.

[14] Y. You, H. Luedeke, and K. Hannemann, "Injection and mixing in a scramjet combustor: DES and RANS studies," Proceedings of the Combustion Institute, vol. 34, no. 2, pp. 2083-2092, 2013.

[15] A. Mangeot, N. Gascoin, and P. Gillard, "Methodologies for detailed chemistry computation application to hybrid rocket combustion chamber simulations," in Proceedings of the 49th AIAA/ASME/SAE/ASEE Joint Propulsion Conference, AIAA, San Jose, Calif, USA, 2013.

[16] K. Park, P.-K. Oh, and H.-J. Lim, "The application of the CFD and Kriging method to an optimization of heat sink," International Journal of Heat and Mass Transfer, vol. 49, no. 19-20, pp. 3439-3447, 2006.

[17] P. Dagaut, A. El Bakali, and A. Ristori, "The combustion of kerosene: experimental results and kinetic modelling using 1to 3-component surrogate model fuels," Fuel, vol. 85, no. 7-8, pp. 944-956, 2006.

[18] P. Dagaut, F. Karsenty, G. Dayma et al., "Experimental and detailed kinetic model for the oxidation of a Gas to Liquid (GtL) jet fuel," Combustion and Flame, vol. 161, no. 3, pp. 835-847, 2014.

[19] S. Honnet, K. Seshadri, U. Niemann, and N. Peters, "A surrogate fuel for kerosene," Proceedings of the Combustion Institute, vol. 32, pp. 485-492, 2009.

[20] P. Dagaut and M. Cathonnet, "The ignition, oxidation, and combustion of kerosene: a review of experimental and kinetic modeling," Progress in Energy and Combustion Science, vol. 32, no. 1, pp. 48-92, 2006.

[21] M. Zhang, Z. Zhu, G. He, and P. Liu, "Large-eddy simulation of kerosene spray combustion in a model scramjet chamber," Proceedings of the IMechE Part G: Journal of Aerospace Engineering, vol. 224, no. 9, pp. 949-960, 2010. 
[22] T. S. Wang, “Thermophysics characterization of kerosene combustion," Journal of Thermophysics and Heat Transfer, vol. 15, no. 2, pp. 140-147, 2001.

[23] D. J. Hautman, F. L. Dryer, K. P. Schug, and I. Glassman, "A multi-step overall kinetic mechanism for the oxidation of hydrocarbons," Combustion Science and Technology, vol. 25, no. 5, pp. 219-235, 1981.

[24] G. Y. Gerasimov and S. A. Losev, "Kinetic models of combustion of kerosene and its components," Journal of Engineering Physics and Thermophysics, vol. 78, no. 6, pp. 1059-1070, 2005.

[25] S. K. Srlvatsa, "Computations of soot and NOX emissions from gas turbine combustors," NASA CR-167930, 1982.

[26] J.-S. Park, "Optimal Latin-hypercube designs for computer experiments," Journal of Statistical Planning and Inference, vol. 39, no. 1, pp. 95-111, 1994.

[27] J. Yim, B. J. Lee, and C. Kim, "Exploring multi-stage shape optimization strategy of multi-body geometries using Krigingbased model and adjoint method," Computers \& Fluids, vol. 68, pp. 71-87, 2012.

[28] F. Boukouvala and M. G. Ierapetritou, "Feasibility analysis of black-box processes using an adaptive sampling Kriging-based method," Computers \& Chemical Engineering, vol. 36, no. 1, pp. 358-368, 2012.

[29] R. A. Baurle, T. Mathur, M. R. Gruber, and K. R. Jackson, "A numerical and experimental investigation of a scramjet combustor for hypersonic missile applications," AIAA Paper 983121, 1998.

[30] iSIGHT software, http://www.simulia.com. 


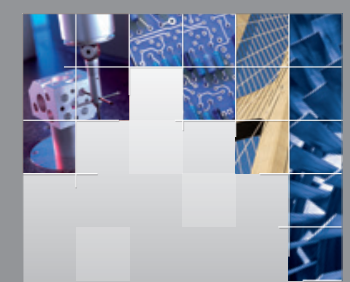

\section{Enfincering}
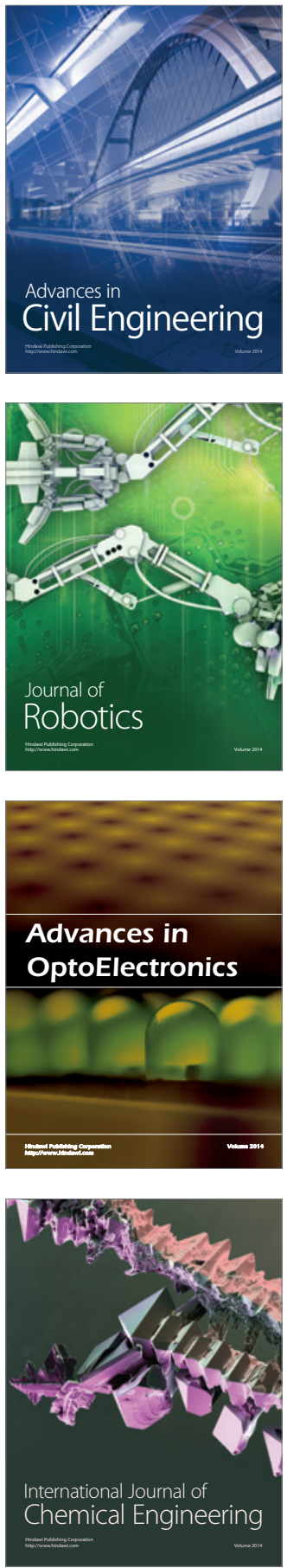

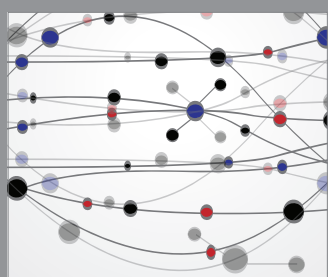

The Scientific World Journal

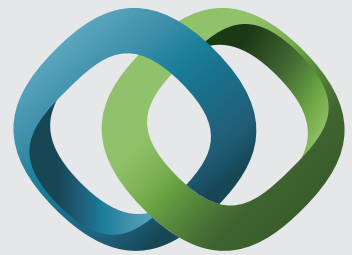

\section{Hindawi}

Submit your manuscripts at

http://www.hindawi.com
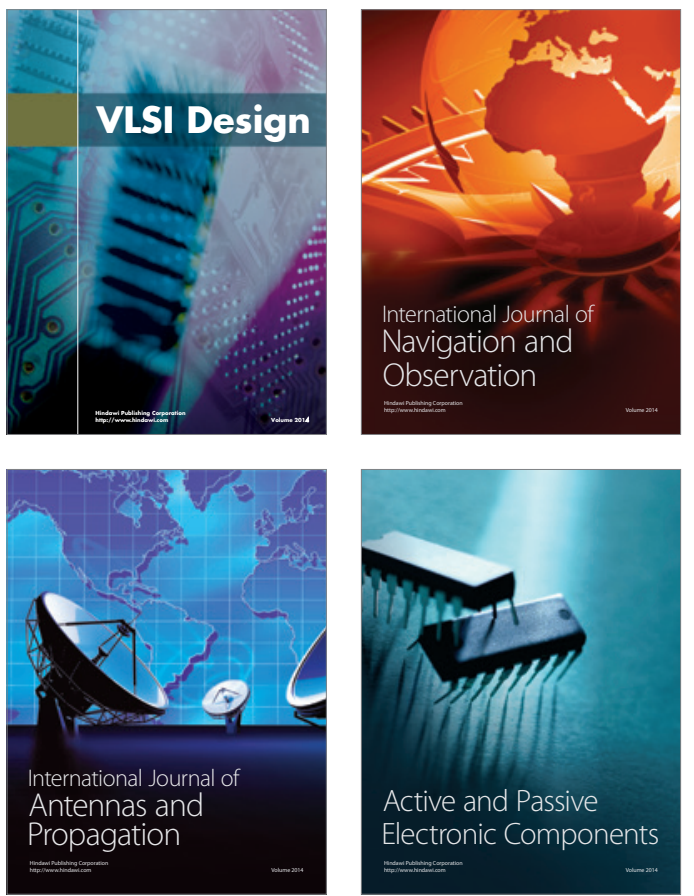
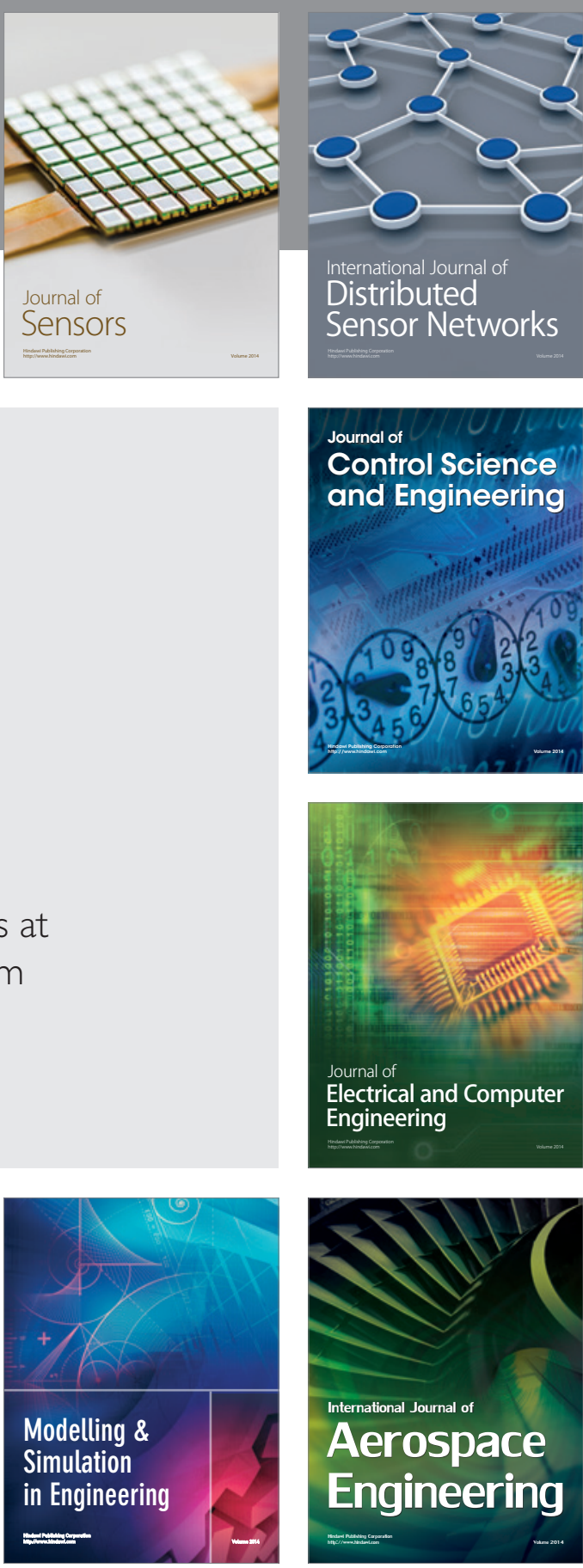

International Journal of

Distributed

Sensor Networks

Journal of

Control Science

and Engineering
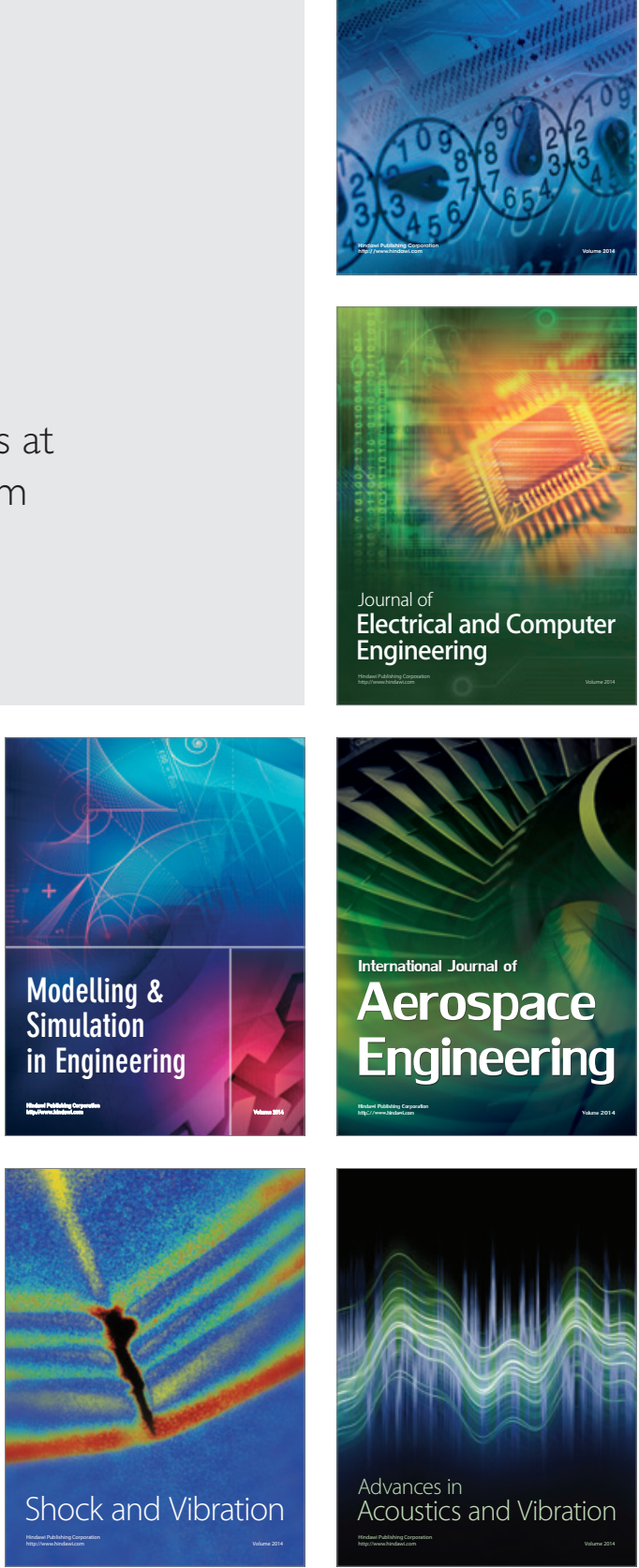